\title{
UTILIZING LANDSAT AND SENTINEL-2 TO REMOTELY MONITOR AND EVALUATE THE PERFORMANCE OF WINTER COVER CROPS THROUGHOUT MARYLAND
}

\author{
Julio Peredo ${ }^{1, *}$, Callum Wayman ${ }^{1}$, Benjamin Whong ${ }^{1}$, Alison Thieme ${ }^{1}$, Logan R. Kline ${ }^{1}$, Sunita Yadav $^{1}$, Bryan Eder ${ }^{1}$, Victor Lenske ${ }^{1}$, \\ Diane Portillo ${ }^{1}$, Sean McCartney ${ }^{1}$, John Fitz ${ }^{1}$, Perry Oddo ${ }^{1}$, Jason Keppler ${ }^{2}$, Dean Hively ${ }^{3}$, John Bolten ${ }^{4}$, Greg McCarty ${ }^{5}$, Adam Lyon ${ }^{2}$ \\ ${ }^{1}$ Science Systems and Applications Inc. at NASA Goddard Space Flight Center, 8800 Greenbelt Road, Greenbelt, MD 20771 - \\ juliop1@umbc.edu, (callum.wayman, benjaminwhong, alisonthieme, logan.kline1997,dr.biogeo)@gmail.com, beder@terpmail.umd.edu, \\ (victor.lenske, dianeportillo26)@gmail.com, sean.mccartney@nasa.gov,johnfitz058@gmail.com, perry.oddo@nasa.gov \\ ${ }^{2}$ Maryland Department of Agriculture, Annapolis, MD 21401 - (jason.keppler, adam.lyon)@maryland.gov \\ ${ }^{3}$ USGS Lower Mississippi Gulf Science Center, Beltsville, MD 20705 - whively@usgs.gov \\ ${ }^{4}$ NASA Goddard Space Flight Center, 8800 Greenbelt Road, Greenbelt, MD 20771 - john.bolten@nasa.gov \\ ${ }^{5}$ USDA-ARS Hydrology \& Remote Sensing Laboratory, Beltsville Agricultural Research Center, Beltsville MD 20705 - \\ greg.mccarty@ars.usda.gov
}

KEY WORDS: Remote Sensing, Graphical User Interface, Google Earth Engine, Normalized Difference Vegetation Index, Biomass, Percent Ground Cover, Time Series

\begin{abstract}
:
Winter cover crops have been shown to limit erosion and nutrient runoff from agricultural land. To promote their usage, the Maryland Department of Agriculture (MDA) subsidizes farmers who plant cover crops. Conventional verification of cover crop planting and analysis of subsequent crop performance requires on-the-ground fieldwork, which is costly and labor intensive. In partnership with the MDA, NASA's DEVELOP program utilized imagery from Landsat 5, Landsat 8, and the European Space Agency's Sentinel-2 to create a decision support tool for satellite-based monitoring of cover crop performance throughout Maryland. Our teams created CCROP, an interactive graphical user interface, in Google Earth Engine which analyzes satellite imagery to calculate the normalized difference vegetation index (NDVI) of fields across the state. Linear regression models were applied to convert NDVI to estimates of crop biomass and percent green ground cover, with measure of fit $\left(\mathrm{R}^{2}\right)$ values ranging from 0.4 to 0.7 . These crop metrics were implemented into an interactive filtering tool within CCROP which allows users to examine cover crop performance based on a variety of growing parameters. CCROP also includes a time series analysis routine for examining the progression of NDVI throughout the spring to help determine farmer-induced termination dates of cover crops. With this decision support tool, the MDA can analyze the effectiveness of cover crops throughout the state with reduced need to manually spot-check enrolled production fields, and can identify variables influencing overall cover crop performance to optimize implementation of their winter cover crop program via adaptive management approaches.
\end{abstract}

\section{INTRODUCTION}

\subsection{Background Information}

The Chesapeake Bay is the largest estuary in the United States, fed by a watershed spanning six states and encompassing $166,000 \mathrm{~km}^{2}$ of diverse terrestrial and marine ecosystems (Phillips, McGee, 2016). Over 3,000 species of bivalves, birds, fish, and other organisms inhabit the watershed, and nearby coastal wetlands provide nurseries, food, and nesting sites (Chesapeake Bay Foundation, n.d.). The Chesapeake Bay also generates substantial commercial benefits, hosting a multibillion dollar boating industry and fisheries capable of generating \$2 billion per year (Maryland Department of Natural Resources, 2012). Therefore, the health of the Bay and neighboring watersheds is of great ecological and economic importance to the Mid-Atlantic region. However, soil erosion and nutrient leaching from agricultural lands pose a major threat to the estuary and its local waterways (Dauer et al., 2000). Sediment loading from farms can bury benthic organisms, prevent sunlight from reaching submerged aquatic vegetation, and transport nutrients such as nitrogen into vulnerable habitats (Gellis et al., 2004). Excess nitrogen can induce eutrophication and subsequent hypoxia in coastal waters, threatening the prolific fisheries of the Chesapeake Bay (Boesch et al., 2001; Malone et al., 1993).

"Cover crop" is a term used to refer to crops, typically large grains, which are planted in between growing seasons for the sake of nutrient retention and soil preservation (Dabney et al., 2001). Cover crops are a valuable component in land-use strategies for agroecosystems and provide a diverse set of benefits including soil enrichment, erosion reduction, and protection against nutrient loss (Hively et al., 2009). Their role in nitrogen and phosphorus uptake, as well as runoff prevention, improves water quality (Boesch et al., 2001). To promote cover crop use for Chesapeake Bay conservation, the Maryland Department of Agriculture (MDA) oversees the Maryland Agricultural Water Quality Cost-Share (MACS) Program, which offers subsidies to Maryland farmers who plant winter cover crops.

The effectiveness of cover crops depends on management practices and agronomic factors such as planting date, method, and crop species (Hively et al., 2009). Routine, accurate monitoring of cover crops is difficult using traditional methods. However, biomass, the total mass of vegetation in a given area, and normalized difference vegetation index (NDVI), a

*Corresponding author 
commonly used indicator of green vegetation estimated by remote sensing techniques, are metrics which can reliably be used to evaluate cover crop performance (Hively et al., 2009; Prabahakara et al., 2015). To this end, satellite-based remote sensing can be used as a method to efficiently assess regional cover crop performance on a routine basis. Furthermore, the employment of remote sensing techniques can result in the accurate calculation and attainment of both biomass measurements and NDVI values.

The NASA DEVELOP program partnered with the MDA, the United States Geological Survey (USGS), and the United States Department of Agriculture (USDA) to create cover crop analysis procedures in Maryland. This two-year partnership began in the spring of 2017, when statistical analysis was performed to establish correlations between remotely sensed NDVI values and two more directly applicable performance metrics: biomass and percent ground cover (Thieme et al., submitted manuscript, 2019). They also automated the acquisition and analysis of satellite imagery via code in Google Earth Engine (GEE) and R (R Core Team, 2017) for the purpose of examining cover crop performance in four Maryland counties: Talbot, Somerset, Queen Anne's and Washington. The next stage of this partnership, which began in the fall of 2018, expanded the study area to the entire state of Maryland and created a graphical user interface (GUI) called CCROP in GEE to optimize end user analysis of cover crop data. This tool provided the Maryland Department of Agriculture (MDA) with a means to remotely verify cover crop growth and better visualize cover crop performance metrics via quantitative summary tables. These tabular outputs displayed cover crop data such as biomass, percent ground cover, and NDVI values of selected counties based on chosen GUI filtering methods. The final stage, beginning in the spring of 2019 , concluded the partnership and focused on springtime analysis of cover crops and finalizing CCROP functionality. The team used the existing GEE GUI framework to incorporate an NDVI-based time series for the purpose of monitoring cover crops throughout their lifecycle. This added feature provides a user-friendly method to visualize crucial cover crop performance data such as per-pixel NDVI values, above ground biomass measurements, and planting and termination dates across the state of Maryland.

This project's study area included fields enrolled in the MDA's cover crop program across the state of Maryland (Figure 1). The final DEVELOP team focused on data from the winter (December 1 - January 31) and spring (March 1 - May 31) seasons from December 2006 to March 2019.

\subsection{Project Partners \& Objectives}

Project development was conducted in collaboration with the MDA Office of Resource Conservation (ORC), the USGS Eastern Geographic Science Center (EGSC), the USDA Agricultural Research Service (ARS), and the Environmental Protection Agency (EPA) Chesapeake Bay Program (CBP).

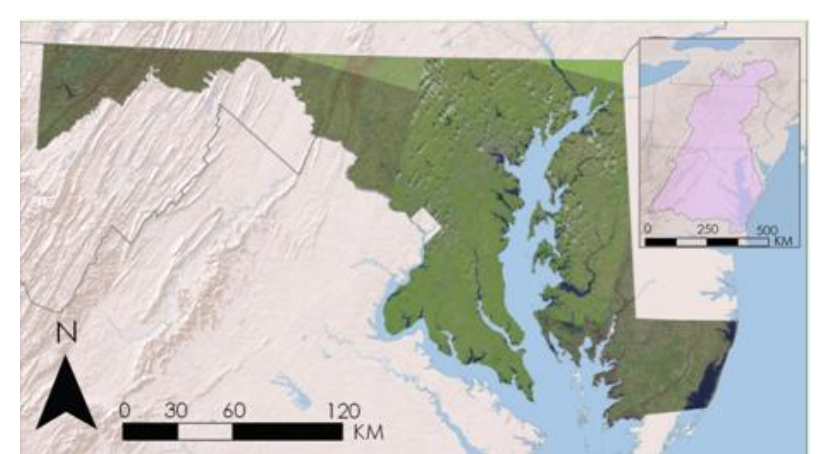

Figure 1. Study area, Maryland, as a mosaic of Landsat 8 OLI images. The Chesapeake Bay watershed is highlighted in the inset. Source: Landsat 8 OLI (NASA), Maryland County Boundaries (Maryland GIS Data Catalog), World Shaded Relief(ESRI), State Boundaries (ESRI).

\section{METHODOLOGY}

\subsection{Data Acquisition}

This project relies primarily on NASA Earth observations for its remote sensing analysis. The project teams used NASA Landsat archival imagery (atmospherically corrected to determine surface reflectance) and European Space Agency (ESA) Sentinel-2 imagery. These data were imported from the GEE repository for various winter cover crop planting seasons lasting from August to May. Data were analyzed for winter (December 15-January 31) and spring (March 1-May 31) from December 2014 to March 2019. See Table 1 for a complete description of sensors used.

Partners at USGS and USDA-ARS provided field-measured crop samples, which were pre-processed and used to develop calibration equations for converting NDVI into biomass and percent ground cover estimates, per Thieme et al. (submitted 2019).

The MDA provided ArcGIS-generated shapefiles (ESRI, Redlands, CA) containing management practice information and field boundaries for each field enrolled in the cover crop program. Data were received for 23 Maryland counties from 2017 to 2019. Prior to 2017, shapefiles of enrolled fields were provided for four counties: Talbot, Somerset, Queen Anne's and Washington.

\begin{tabular}{|l|l|l|l|}
\hline $\begin{array}{l}\text { Platform } \\
\text { \& Sensor }\end{array}$ & Level & $\begin{array}{l}\text { Google Earth Engine Image } \\
\text { Collection IDs }\end{array}$ & $\begin{array}{l}\text { Available } \\
\text { Years }\end{array}$ \\
\hline $\begin{array}{l}\text { Landsat 5 } \\
\text { TM }\end{array}$ & 2 & LANDSAT/LT05/C01/T1_SR & $\begin{array}{l}2006- \\
2012\end{array}$ \\
\hline $\begin{array}{l}\text { Landsat 8 } \\
\text { OLI }\end{array}$ & 2 & LANDSAT/LC08/C01/T1_SR & $\begin{array}{l}2013- \\
2019\end{array}$ \\
\hline $\begin{array}{l}\text { Sentinel-2 } \\
\text { MSI }\end{array}$ & $1 \mathrm{C}$ & COPERNICUS/S2 & $\begin{array}{l}2015- \\
2019\end{array}$ \\
\hline
\end{tabular}

Table 1. Remote sensing products utilized in the development of CCROP. 


\subsection{Data Processing}

Field shapefiles provided by the MDA and projected via the 1984 World Geodetic System (WKID 4326) were uploaded to GEE as tabular data. A 15-meter inner buffer was applied to diminish edge effects and refine field boundaries. This resulted in loss of fields whose geometry was contained entirely within this buffered region. An additional Maryland state boundary shapefile was imported, and Landsat and Sentinel-2 image collections were spatially filtered via these boundaries. The image collection was temporally filtered to include data acquired during pre-defined winter and spring intervals (December 15-January 31 and March 1-May 31, respectively).

The image collection for each season was then passed into our graphical user interface, CCROP, where it underwent three stages of processing. The CFmask algorithm, a multi-pass algorithm that uses decision trees to classify scenes pixel by pixel (United States Geological Survey, n.d.), was applied to remove cloud-covered pixels in Landsat and Sentinel-2 images. CCROP then inserted a property that denotes the date of image collection. Finally, NDVI was calculated on a pixel level using the standard NDVI equation (Equation 1):

$$
\mathrm{NDVI}=\frac{(\mathrm{NIR}-\mathrm{Red})}{(\mathrm{NIR}+\mathrm{Red})}
$$

These per-pixel NDVI values are displayed in the user interface for selected counties and dates.

\subsection{Data Analysis}

The maximum average NDVI values for each field in a selected season were used to calculate biomass and percent ground cover using linear regression equations calculated with the partner-provided calibration data (Table 2).

\begin{tabular}{|l|l|l|l|}
\hline $\begin{array}{l}\text { Performance } \\
\text { Variable }\end{array}$ & Season & Equation & $\mathbf{R}^{2}$ \\
\hline Biomass & Winter & $\begin{array}{l}\text { ln(biomass) }=3.2022+ \\
5.3740 * \text { NDI }\end{array}$ & 0.562 \\
\hline Biomass & Spring & $\begin{array}{l}\ln (\text { biomass })=4.7794+ \\
3.7453 * \text { NDI }\end{array}$ & 0.403 \\
\hline $\begin{array}{l}\text { Percent ground } \\
\text { cover }\end{array}$ & Winter & $\begin{array}{l}\text { PGC }=-21.904+ \\
116.305^{*} \text { NDVI }\end{array}$ & 0.685 \\
\hline $\begin{array}{l}\text { Percent ground } \\
\text { cover }\end{array}$ & Spring & $\begin{array}{l}\text { PGC = -10.783 + } \\
107.566 * \text { NDVI }\end{array}$ & 0.624 \\
\hline
\end{tabular}

Table 2. Calibration models to predict biomass and percent vegetative ground cover from satellite-derived NDVI (adapted from Thieme et al., submitted 2019).

Biomass is then calculated by exponentiating these results, as per Equation 2 (Thieme et al., submitted 2019):

$$
\text { Biomass }=e^{\ln (\text { Biomass })+\frac{M S E}{2}}
$$

where MSE represents the mean squared error.

The approximate amount paid to each farmer for cover crop yield per kilogram of nitrogen is calculated using the subsidy rates provided by the MDA. This calculation is made according to Equation 3:

$$
\text { CostField }=\frac{\text { Rate }}{\left(\frac{\text { Biomass }}{2.47105 * 50}\right)}
$$

where Rate denotes the amount of money in USD paid to each farmer per acre and Biomass denotes the biomass of each field in $\mathrm{kg}$ of nitrogen per hectare. This biomass number is converted to $\mathrm{kg}$ of nitrogen per acre and divided by 50 based on the assumption that nitrogen uptake can be approximated as $2 \%$ of total biomass (Hively et al., 2009).

After data is analyzed for a season, CCROP was used to display NDVI values at the pixel scale for all enrolled fields on a given date. Days that can be displayed are dependent on the temporal resolution of remote sensing datasets. Sentinel-2's temporal resolution ( 5 days) is significantly higher than that of Landsat 5 and Landsat 8 (16 days). Imagery from the two satellites are not comparable as Sentinel-2 surface reflectance has yet to be fully incorporated in GEE; Sentinel-2 top of atmosphere data was used instead. In addition to NDVI, CCROP also can visualize biomass and percent ground cover values that are derived from the aforementioned linear regression equations.

\section{RESULTS AND DISCUSSION}

\subsection{Derivation and Visualization of Filtered Agricultural Parameters}

Thieme et al. (submitted 2019) established a reasonably strong $\left(\mathrm{R}^{2}=0.554-0.698\right)$ correlation between NDVI and agronomic parameters; these results are the groundwork by which CCROP conducts its analysis. These correlations varied depending on season and agronomic factor (Table 2).

CCROP provides a number of options for filtering a dataset to examine cover crop performance based on various factors. Experimentation with various combinations of these can yield insight into how to maximize cover crop effectiveness; for this study, patterns were identified in cover crop type and planting date. Figures 2 and 3 display the distribution of max NDVI for wheat fields in Queen Anne's County in spring 2018 versus max NDVI for triticale fields in the same county and time period. 


\section{Graph created based on the following filters:}

Satellite used: L8

Season: Spring

County: Queen Anne's

Cover Crop: Wheat

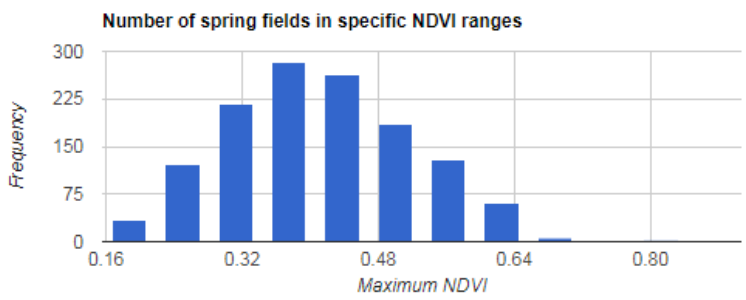

Figure 2. CCROP output histogram displaying number of fields versus NDVI for wheat fields in Queen Anne's County.

Graph created based on the following filters:

Satellite used: $L 8$

Season: Spring

County: Queen Anne's

Cover Crop: Triticale

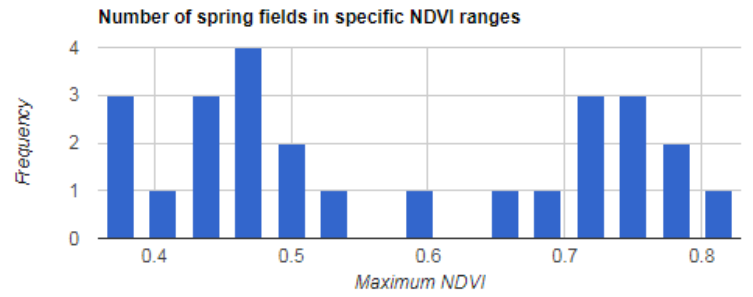

Figure 3. CCROP output histogram displaying number of fields versus NDVI for triticale fields in Queen Anne's County.

In these figures, triticale displays an average NDVI value of 0.56 while wheat displays an average of 0.38 , which equates to a $47 \%$ difference in NDVI between the two crops. Although the sample size for triticale is comparatively smaller than that for wheat, these results suggest that triticale cover crops may perform better than wheat in Queen Anne's County. The user may then repeat this analysis in another county, or over the region as a whole, to examine this pattern in further detail.

CCROP can also be used to test scientific hypotheses on cover crop effectiveness. Prior studies have shown that cover crops are more effective if planted in early fall (Hively et al., 2009). To verify this, different planting date ranges can be selected in CCROP to examine the performance of cover crops planted in September 2017 (Figure 4) compared to those planted in November 2017 (Figure 5).

\section{Graph created based on the following filters:}

Satellite used: L8

Season: Winter

Month: September

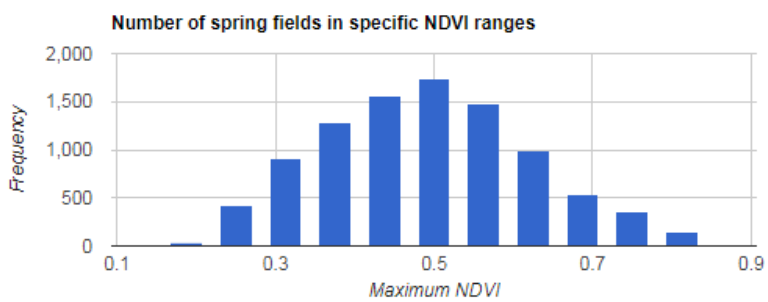

Figure 4. CCROP output histogram showing number of fields versus maximum NDVI for fields planted in September.

\section{Graph created based on the following filters:}

Satellite used: L8

Season: Winter

Month: November

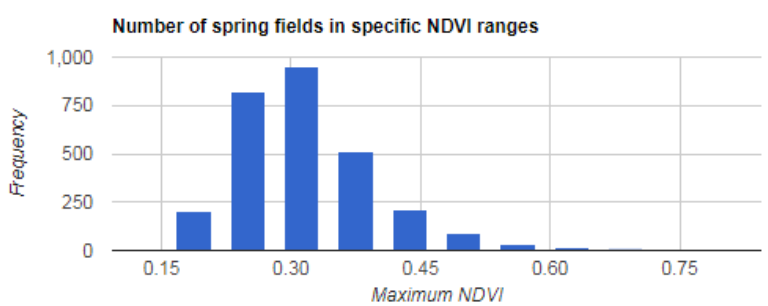

Figure 5. CCROP output histogram showing number of fields versus maximum NDVI for fields planted in November.

These figures support the hypothesis that early planting, before October 1, yields better cover crop performance: the NDVI peak of the November curve is nearly 0.2 lower than the September curve, corresponding to a difference of $20 \%$ ground cover (per the conversion equation in Table 2).

\subsection{Time Series Analysis of Cover Crop Life Cycles}

A time series component was added to CCROP to employ operational remote sensing technology for the purposes of assessing cover crop performance over time and identifying crop termination dates. This new functionality harnesses CCROP's ability to analyze imagery from both Landsat 8 and Sentinel-2 satellites, an integration which improves temporal coverage within the boundaries of our study area. CCROP produces histograms and imagery displaying the distribution of NDVI values on a county level for each date with available data. Comparing outputs from various days in the season reveals long-term trends in cover crop performance. Additionally, by examining GUI output from dates near the termination deadlines, possible crop kill dates can be identified based on changes in NDVI. Figures 6 and 7 display NDVI distributions for Kent County, MD, for December 21, 2017 and March 18, 2018, respectively. 
The frequency distributions in Figures 6 and 7 demonstrate the change in amount of vegetation present in the enrolled cover crop fields in Kent County using two specific days as points of comparison: December 21, 2017 and March 18, 2018. These dates were selected for comparison due to the fact that they fell within the cover crop growing season, had limited cloud cover interference, and allowed a significant time margin for analysis. After the histograms were output by CCROP's time series tool, the data were sorted to determine the percentage of fields which fell below the MDA-provided NDVI threshold of 0.3 , a cut-off value that denotes either low performing or terminated fields. On December 21st, approximately $8 \%$ of enrolled cover crop fields in Kent County fell below this threshold. On March 18 th, approximately $22 \%$ of cover crop fields in Kent County were below 0.3 NDVI, marking a $157 \%$ relative increase over this time period. This percentage increase in low NDVI fields is a significant finding as it suggests that a significant portion of Kent County cover crops were killed off within the earliest termination window set by the MDA, March 1st to March 15th.

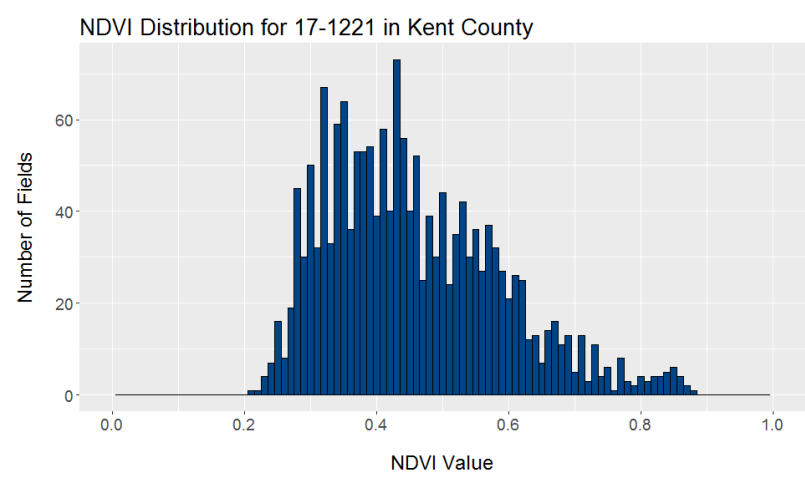

Figure 6. NDVI histogram of enrolled fields in Kent County, Landsat imagery on December 21, 2017. Date is displayed as YY-MMdd.

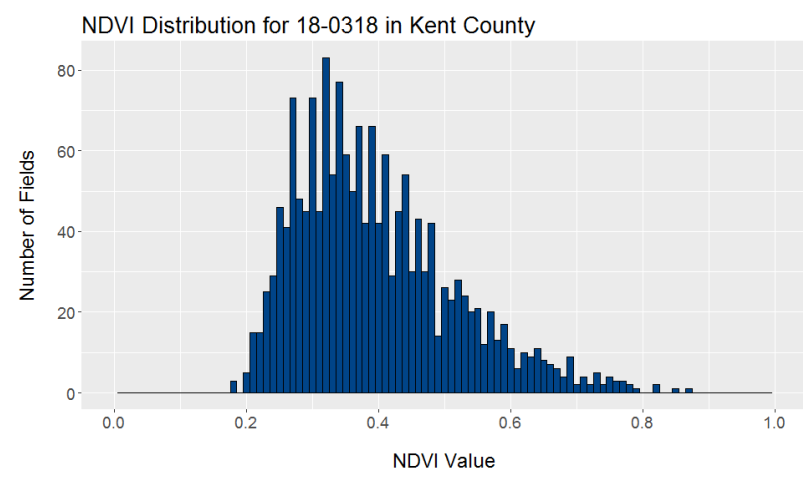

Figure 7. NDVI histogram of enrolled fields in Kent County, Landsat imagery on March 18, 2018. Date is displayed as YYMMdd.

CCROP can be used to perform similar analysis for all Maryland counties, provided cloud-free data is available over the entire region for the dates of interest. Table 3 displays percentages of low NDVI fields for various Maryland counties in winter and spring.

\begin{tabular}{|l|l|l|l|}
\hline County & $\begin{array}{l}\text { Low perfor- } \\
\text { ming } \\
\text { December } \\
\text { fields (\%) }\end{array}$ & $\begin{array}{l}\text { Low perfor- } \\
\text { ming March } \\
\text { fields (\%) }\end{array}$ & $\begin{array}{l}\text { Relative } \\
\text { Difference } \\
(\%)\end{array}$ \\
\hline Caroline & 5 & 3 & -40 \\
\hline Cecil & 10 & 21 & +110 \\
\hline Kent & 8 & 22 & +175 \\
\hline Oueen & 9 & 11 & +22 \\
\hline Somerset & 2 & $1 *$ & -50 \\
\hline Talbot & 7 & 11 & +57 \\
\hline Washington & 11 & $15^{*}$ & +36 \\
\hline
\end{tabular}

Table 3. Percentages of low performing (below 0.3 NDVI)

fields for various Maryland counties in winter and spring.

*Denotes use of April imagery when no high-quality March imagery was available

Table 3 supports the results found in Kent and Talbot counties; of the Maryland counties examined, five out of seven had a higher ratio of low NDVI in the spring, and the two counties that display the opposite trend show relatively small disparity between winter and spring values. Cover crop effectiveness is positively correlated with the duration of time that the crops remain alive in the spring (Lyon, personal communication, 2019). Therefore, it is significant that such a large proportion of cover crops in multiple counties are eliminated in these early weeks.

While differences in crop termination dates can explain the above findings, it is important to note that numerous factors, such as cover crop type and planting dates of traditional harvest crops, can affect the results. The latter may mask observed termination dates when farmers plant new crops soon after cover crop termination given the GUI's current inability to conduct land/crop classification. NDVI values alone indicate only vegetation presence, not type. An uncertain amount of observed springtime greenness is caused by fields that may contain non-cover crop vegetation. However, in this case, these false positives could increase the average NDVI for fields in which they were present, thus reducing the ratio of low NDVI fields calculated with CCROP.

\section{CONCLUSIONS}

Developed in partnership with the Maryland Department of Agriculture, CCROP has potential to bolster the MDA's current decision making process regarding cover crop management practices. CCROP provides both scientific and practical benefits to this end. Scientifically, its filtering ability allows users to examine cover crop effectiveness with various permutations of management practices to determine the conditions that yield the best performance. For instance, CCROP's outputs suggest that wheat, the most commonly planted cover crop, has a lower-skewing maximum NDVI distribution than its less common counterpart, triticale. 
Practically, CCROP's time series feature enables users to detect trends in NDVI over time, potentially including remote identification of springtime crop termination. This would reduce the MDA's need to manually verify termination on fields individually, freeing time and resources for other conservation efforts. This project demonstrates the potential to apply NASA Earth observations and other remote sensing data to agriculture and conservation purposes on a statewide scale. As this technology improves, so will CCROP's capabilities; integration of Sentinel-2 surface reflectance, for instance, would enable unification of Landsat and Sentinel data to create a more temporally contiguous time series.

\section{ACKNOWLEDGMENTS}

This material contains modified Copernicus Sentinel data (2017-2019), processed by ESA.

Any opinions, findings, and conclusions or recommendations expressed in this material are those of the author(s) and do not necessarily reflect the views of the National Aeronautics and Space Administration.

This material is based upon work supported by NASA through contract NNL16AA05C.

\section{REFERENCES}

Boesch, D.F., Brinsfield, R.B., Magnien, R.E., 2001. Chesapeake bay eutrophication. Journal of Environmental Quality 30, 303-320.

Chesapeake Bay Foundation, n.d.. Chesapeake wildlife. URL: http://www.cbf.org/about-the-bay/more-than-just-thebay/chesapeake-wildlife/

Dabney, S.M., Delgado, J.A., Reeves, D.W., 2001. Using winter cover crops to improve soil and water quality. Communications in Soil Science and Plant Analysis $32,1221-1250$.

Dauer, D.M., Ranasinghe, J.A., Weisberg, S.B., 2000. Relationships between benthic community condition, water quality, sediment quality, nutrient loads, and land use patterns in Chesapeake Bay. Estuaries 23, $80-96$.

Gellis, A.C., Banks, W.S., Langland, M.J., Martucci, S.K., 2004. Summary of suspended-sediment data for streams draining the Chesapeake Bay watershed, water years 1952-2002. US Geological Survey Scientific Investigations Report 5056, 1-59.

Hively, W.D., Duiker, S., McCarty, G., Prabhakara, K., 2015. Remote sensing to monitor cover crop adoption in southeastern Pennsylvania. Journal of Soil and Water Conservation 70, 340-352. https://doi.org/10.2489/jswc. 70.6 .340

Hively, W.D., Lang, M., McCarty, G.W., Keppler, J., Sadeghi, A., McConnell, L.L., 2009. Using satellite remote sensing to estimate winter cover crop nutrient uptake efficiency. Journal of Soil and Water Conservation 64, 303-313. https://doi.org/10.2489/jswc.64.5.303

Malone, T.C., Boynton, W., Horton, T., Stevenson, C., 1993. Nutrient loadings to surface waters: Chesapeake Bay case study. Keeping pace with science and engineering: Case studies in environmental regulation 8-38. Retrieved from: https://www.nap.edu/read/2127/chapter/3

Maryland Department of Natural Resources, 2012. Accounting for Maryland's Ecosystem Services: Integrating the value of nature into decision making. Maryland Department of Natural Resources, Annapolis, MD.

Phillips, S., McGee, B., 2016. Ecosystem service benefits of a cleaner Chesapeake Bay. Coastal Management 44, 241-258. https://doi.org/10.1080/08920753.2016.1160205

Prabhakara, K., Hively, W.D., McCarty, G.W., 2015. Evaluating the relationship between biomass, percent groundcover and remote sensing indices across six winter cover crop fields in Maryland, United States. International Journal of Applied Earth Observation and Geoinformation 39, 88-102. https://doi.org/10.1016/j.jag.2015.03.002

R Core Team (2017). R: A language and environment for statistical computing. R Foundation for Statistical Computing, Vienna, Austria. http://www.Rproject.org/

Thieme, A., Yadav, S., Oddo, P. C., Fitz, J. M., McCartney, S., King, L., Keppler, J., McCarty, G., Hively, W. D., 2019. Using NASA Earth Observations and Google Earth Engine to Map Winter Cover Crop Conservation Performance in the Chesapeake Bay Watershed. Manuscript submitted for publication.

United States Geological Survey, n.d.. What is the C Function of Mask (CFMask) Algorithm? Retrieved from: https://landsat.usgs.gov/what-cfmask 